SMAD, Rev. Eletrônica Saúde Mental Álcool Drog.

\title{
Perspectiva do usuário de drogas sobre seu tratamento e a rede de atenção psicossocial*
}

\section{Vanessa Ayres Tibiriçá 1 \\ (D) https://orcid.org/0000-0002-8035-3898 \\ Eduarda Pampolin Miessi Luchini ${ }^{1}$ \\ (D) https://orcid.org/0000-0002-5016-982X \\ Camila Souza de Almeida ${ }^{1,2}$ \\ (ID https://orcid.org/0000-0002-7032-0945}

* Apoio financeiro do Programa Institucional de Apoio à Pesquisa (PAPQ) da Universidade Estadual de Minas Gerais, Brasil, processo no 16711655-17.

${ }^{1}$ Universidade do Estado de Minas Gerais, Divinópolis, MG, Brasil.

2 Universidade Federal de Minas Gerais, Belo Horizonte, MG, Brasil.
Objetivo: analisar a percepção do usuário de álcool e outras drogas sobre seu tratamento em um Centro de Atenção Psicossocial de álcool e outras drogas e de sua inserção na Rede de Atenção Psicossocial. Método: trata-se de uma pesquisa qualitativa exploratória, na qual se utilizaram grupos focais como forma de coleta de dados. O estudo ocorreu na cidade de Divinópolis, Minas Gerais, no período de agosto a novembro de 2017. Resultados: ao todo foram cinco grupos focais em que se abordaram temas como tratamento, percurso na Rede assistencial e relação com o Sistema de Saúde da cidade. Conclusão: a Rede de Atenção Psicossocial se encontra muito fragmentada e fragilizada, o que dificulta o tratamento do usuário de álcool e outras drogas e sobrecarrega os serviços especializados em saúde mental.

Descritores: Transtornos Relacionados ao uso de Substâncias; Saúde Mental; Serviços de Saúde Mental; Enfermagem; Integralidade em Saúde.

\section{Como citar este artigo}

Tibiriçá VA, Luchini EPM, Almeida CS. Drug users' perspective on their treatment and the psychosocial care network. SMAD, Rev Eletrônica Saúde Mental Álcool Drog. 2019;15(3):1-9. doi: https://dx.doi.org/10.11606/issn.1806-6976.smad.2019.150890 


\section{Drug users' perspective on their treatment and the psychosocial care network}

Objective: to analyze the perception of the user of alcohol and other drugs on their treatment in a Psychosocial Care Center for alcohol and other drugs and their insertion in the psychosocial care network. Method: this is an exploratory qualitative research, in which focal groups were used as a way of collecting data. The study was conducted in the city of Divinópolis, Minas Gerais, from August to November 2017. Results: in all, five focus groups addressed issues such as treatment, care network and relationship with the city's health system. Conclusion: the psychosocial care network is very fragmented and fragile, which makes it difficult for the users of alcohol and other drugs to be treated and overload the specialized mental health services.

Descriptors: Substance-Related Disorders; Mental Health; Mental Health Services; Nursing; Integrality in Health.

\section{Perspectiva de los usuarios de drogas sobre su red de tratamiento y atención psicosocial}

Objetivo: Analizar la percepción de los usuarios de alcohol y otras drogas sobre su tratamiento en un Centro de Atención Psicosocial para el alcohol y otras drogas y su inserción en la Red de Atención Psicosocial. Método: Esta es una investigación cualitativa exploratoria, en la que se utilizaron grupos focales como una forma de recopilación de datos. El estudio tuvo lugar en la ciudad de Divinópolis, Minas Gerais, de agosto a noviembre de 2017. Resultados: en total, hubo cinco grupos focales que abordaron temas como el tratamiento, la ruta de atención y la relación con el sistema de salud de la ciudad. Conclusión: La Red de Atención Psicosocial está muy fragmentada y frágil, lo que dificulta el tratamiento de los usuarios de alcohol y otras drogas y sobrecarga los servicios especializados de salud mental.

Descriptores: Trastornos por uso de sustancias; Salud mental; Servicios de salud mental; Enfermería; Integralidad en salud. 


\section{Introdução}

O tratamento ao indivíduo com problemas relacionados ao uso e abuso de substâncias psicoativas (SPA) já perpassou por várias modalidades, sendo na atualidade preconizado o cuidado no território, sem institucionalizações e internações de longa duração(1).

$\mathrm{O}$ indivíduo deveria ter um acompanhamento majoritariamente realizado na Atenção Primária em Saúde (APS), não sendo delegado apenas esse cuidado à Atenção secundária ou terciária. Além disso, a saúde mental de maneira geral deveria ser concebida como ação transversal em toda a rede de saúde, e não apenas como ações pontuais(1).

Os primeiros dispositivos implantados para o cuidado em saúde mental foram os Centros de Atenção Psicossocial (CAPS) implementados em 1989, porém instituídos pela Portaria 224 em 1992, substituída em 2002 pela Portaria no 336. O CAPS foi o dispositivo que possibilitou a desinstitucionalização de milhares de pessoas com oferta de serviços territoriais e reinserção do paciente no seu território.

Em 2003, foi lançada a Política do Ministério da Saúde para Atenção Integral a usuários de álcool e outras drogas, tendo como base os princípios do Sistema Único de Saúde (SUS) e a Reforma Psiquiátrica. As orientações dessa política são o trabalho em rede, a participação do usuário e a criação dos serviços alternativos aos hospitais psiquiátricos. Entre os serviços alternativos estão os Centros de Atenção Psicossocial álcool e outras drogas (CAPS ad), orientados pela estratégia de redução de danos, prevenção, recuperação e reinserção social.

Anterior à publicação da Portaria GM/MS no 3.088/2011, o CAPS era considerado ordenador de todas as demandas de saúde mental do território, responsabilizando-se pela articulação com outras instituições de saúde e redes, como a da assistência social. Com o advento da Portaria de 2011, que instituiu a Rede de Atenção Psicossocial (RAPS), verificou-se a mudança dessa conformação, passando à APS ser a principal forma de articulação da saúde mental no território(2).

Os diferentes componentes da Rede de Atenção Psicossocial devem se articular para tratar e acompanhar os usuários, não devendo restringir-se a si mesma, cabendo-Ihe a articulação Intersetorial, como educação e assistência social, para que, de fato, seja possível o cuidado integral do indivíduo(3).

Os atendimentos integrais dos usuários de álcool e outras drogas na RAPS seriam suficientes para evitar hospitalizações e uso abusivo de medicamentos por parte destes. No entanto, o que se observa na prática é uma grande dificuldade neste sentido, visto que a rede não consegue captar esses indivíduos no início do adoecimento nem fazer o acompanhamento necessário a estes enquanto eles transitam da APS para a Atenção secundária ou terciaria(4).

Quanto ao tratamento nos CAPS ad ainda existem algumas dificuldades referentes à necessidade de quebra do modelo assistencialista, que vem enraizado na saúde e na formação dos profissionais que atuam nessa área. O que se tem ainda é a visão biologicista, em que se trata apenas os sinais e sintomas da doença, não sendo considerados muitas vezes os componentes psicossociais, o que acaba por dificultar o tratamento preconizado pelo Ministério da Saúde.

As universidades e os cursos da área da Saúde, como a enfermagem, ainda não conseguem com seus atuais currículos abranger toda a magnitude necessária para o entendimento do fenômeno do uso de álcool e outras drogas, além do preconceito que ainda existe por parte destes e da sociedade quando se trata de usuários de substâncias psicoativas(4).

Assim como as dificuldades impostas por falta de verba do governo, principalmente com a proposta de Ementa Constitucional no 241, que traduzirá em mudanças que comprometerão o financiamento da APS no Brasil e a qualidade dos serviços prestados.

Os CAPS ad ainda são serviços novos no país, tendo ganhado força após 2011, mas com os possíveis cortes previstos não apenas com a Ementa Constitucional, mas com a resolução no 32, de 14 de dezembro de 2017, que aumenta o financiamento das comunidades terapêuticas e que foi alvo de protestos por parte da sociedade e estudiosos da área, pode haver mudanças substanciais na forma de se trabalhar a Saúde mental nos próximos anos.

Todavia, apesar das dificuldades apresentadas nessa efetivação do cuidado, o caminho para um tratamento digno aos indivíduos em uso abusivo de álcool e outras drogas ainda deve ser pelo fortalecimento dos CAPS ad e da RAPS, pois o Ministério da Saúde os preconiza como dispositivo de tratamento e Redução de Danos (RD) e esta só consegue ser efetiva quando realizada em parceria com o usuário em seu território. Assim, esses indivíduos podem ser empoderados a realizar mudanças em suas vidas, deixando de ser meros espectadores de seus tratamentos para se tornarem protagonistas.

Com base no exposto, entende-se que apenas conhecendo as configurações do CAPS ad e da RAPS e como se dá esse percurso do indivíduo por ela é possível perceber os acertos e erros de maneira a fortalecer a Rede. Para captar esse processo nada melhor do que dar voz ao usuário, uma vez que é ele quem necessita do tratamento e de fato percorre a RAPS em busca não apensas de tratamento médico, mas de inserção social.

Assim, o objetivo deste estudo é analisar a visão do usuário quanto ao Centro de Atenção Psicossocial de álcool e outras drogas em quem faz o tratamento e como é seu percurso pela RAPS. 


\section{Método}

O estudo é de natureza qualitativa, no qual foi utilizada a técnica de grupos focais com pacientes do CAPS ad do tipo III na cidade de Divinópolis, Minas Gerais, Brasil, no período de agosto a novembro de 2017, ao todo foram cinco grupos focais.

Como fundamentação teórica se utilizou a determinação social do processo saúde- doença por se acreditar que o uso de drogas não é apenas um fator biológico ou unicamente social, mas um fenômeno dialético em que as dimensões gerais, particulares e singulares se influenciam e são influenciadas mutualmente ${ }^{(5)}$.

Por se tratar de um serviço substitutivo aberto, a rotatividade dos pacientes é grande e as mudanças de participantes durante os grupos eram esperadas. Em média, o local contava com 35 pacientes por dia, mas a participação média por grupo focal foi de oito a doze. Os convites para a participação dos grupos ocorriam no próprio CAPS ad com os usuários presentes no momento, exceto pacientes que estavam restritos ao leito e menores de 18 anos de idade. Devido também à grande rotatividade não foi possível a checagem das entrevistas pós- transcrição pelos usuários participantes dos grupos.

Os encontros ocorreram no próprio local e tiveram entre uma hora e uma hora e meia de duração e ocorriam semanalmente às quartas-feiras. As entrevistadoras eram estudantes de psicologia e enfermagem do quarto período de graduação que foram treinadas previamente pela docente responsável pelo projeto para a realização dos grupos. Todas as estudantes tinham conhecimento prévio sobre a temática e participavam de projetos relacionados ao uso de drogas com a docente responsável, que é enfermeira e tem como tema de trabalho o uso de álcool e outras drogas. Durante os encontros, outros funcionários ou estudantes não puderam participar para não coibir os presentes.

Os grupos focais foram escolhidos por ser uma forma de coleta de dados coletiva, uma técnica não diretiva que se baseia na tendência humana de formar opinião e atitudes quando estão em interação com outras pessoas $^{(6)}$. Por se tratar de um grupo focal foram utilizados roteiros semiestruturados para nortear a discussão. Cada um dos cinco grupos focais teve um objetivo, como discussão sobre o local de tratamento, gatilhos para recaída e seu manejo, rede social e rede de atenção ao usuário de drogas no município.

Antes do início dos grupos focais, as estudantes e pesquisadora responsável visitaram o local e realizaram a observação de campo. Todas as observações anteriores e durante os grupos focais foram anotadas no diário de campo que auxiliou na análise dos dados. Após as análises dos dados, realizou-se um relatório com os resultados que foi encaminhado para os gestores do local.

Vale ressaltar que todos os participantes foram orientados quanto ao tipo de estudo e assinaram o Termo de Consentimento Livre e Esclarecido (TCLE). Todos os grupos foram gravados e logo depois transcritos na íntegra pelas pesquisadoras. Cada participante recebeu um código alfanumérico para manter o sigilo das informações.

O presente estudo foi aprovado pelo Comitê de Ética em Pesquisa da Universidade do Estado de Minas Gerais, CAAE: 69361717.1.0000.5115, atende às determinações da Resolução 466/12, do Conselho Nacional de Saúde e teve o financiamento por meio de bolsa de iniciação científica do Programa Institucional de Bolsas de Apoio à Pesquisa da Universidade do Estado de Minas Gerais (UEMG).

O referencial teórico utilizado requereu para sua análise um referencial metodológico que conseguisse abarcar as objetividades e subjetividades do objeto. Assim, utilizou-se a técnica de análise hermenêutica dialética por se considerar essa articulação pertinente, por se buscar a compreensão sobre o uso de drogas ao mesmo tempo e que se procurou entender os processos macrossociais do uso(7-8).

\section{Resultados}

O CAPS ad III em questão foi inaugurado em 2015 com atendimento 24 horas e uma capacidade total para 45 pacientes. Participaram em média oito usuários em cada grupo focal realizado, sendo no total 32 participantes nos cinco grupos realizados. A maioria dos participantes eram homens ( $81 \%$ ) e a média de idade entre os participantes do sexo masculino foi de 30 anos ou mais e a das mulheres de 50 anos de idade.

A escolaridade entre os homens foi ensino fundamental completo, já as mulheres tiveram um nível de escolaridade maior, com 33,3\% ensino fundamental completo e $33,3 \%$ ensino médio completo. Quanto ao estado civil, $61,5 \%$ dos homens eram solteiros, em relação às mulheres esse percentual chegou a $83,3 \%$.

Quanto à análise dos grupos focais, emergiram cinco categorias temáticas: "caminhos do uso"; "rede social"; "Rede de Atenção Psicossocial: percurso dos usuários" e "CAPS ad real x CAPS ad preconizado". O presente artigo irá abordar as duas últimas categorias temáticas.

\section{CAPS ad Real X CAPS ad Preconizado}

No primeiro grupo focal, os pesquisadores trabalharam sobre o CAPS ad e foram realizadas perguntas para compreender qual seria o nível de conhecimento dos usuários do local quanto ao que era e qual a função do CAPS ad.

Estes demonstraram que não compreendem de maneira específica o papel do local como redutor de danos, mas, sim, como local a se alcançar a abstinência: (serve) pra parar com o uso. (E4); Eu acho que é uma instituição pra ajudar a gente a parar com o vício, né? Parar com o vício. (E3) 
Essa visão está enraizada na sociedade brasileira, mesmo com os avanços da Reforma Psiquiátrica e das Políticas Públicas, ainda paira sobre os indivíduos a noção de "cura", de que um tratamento efetivo seria o que leva a pessoa a cessar o uso completamente, o que pode sim ser uma meta, mas não a única. O CAPS ad deveria trabalhar melhor a temática para a desconstrução do paradigma da abstinência total, muito focada na visão biologicista de cura do corpo.

Durante as observações de campo e relatos dos profissionais, percebe-se que devido ao pouco tempo de funcionamento e à alta demanda, visto que o local atende toda a população usuária de álcool e outras drogas da cidade, não tendo consultório de rua ou outros dispositivos que trabalhem na lógica da RD, a comunicação entre equipe e usuários se mostra falha, podendo prejudicar o entendimento dos usuários sobre qual o papel da instituição: O certo também é eles (equipe) fazer uma reunião aí, pergunta, conversa com a gente né, mas não tem isso. (E17); Nada disso aqui é falado pra nós (sobre a Redução de danos), nada disso. (E16)

Com esses relatos e com as notas de campo se percebe a dialética presente no local do estudo, em que os profissionais de saúde relatam trabalhar com a redução de danos, mas na prática, seja devido ao enorme volume de trabalho ou até mesmo em virtude da formação profissional, não trabalham o empoderamento do usuário.

Sendo que um dos pilares da RAPS e consequentemente do CAPS ad é a participação do usuário em seu tratamento. Esse indivíduo deve ser considerado como cidadão de direitos e deveres e juntamente com a equipe de saúde construir seu tratamento.

Ainda se tem a hierarquia em que os profissionais de saúde se posicionam como detentores do conhecimento, acreditando que os "pacientes" devem apenas seguir as recomendações, mas dentro da lógica da redução de danos e do tratamento no território seria o paciente a guiar seu tratamento.

Quando questionados sobre como se dá a relação entre a equipe e eles, os relatos demonstraram uma convivência aparentemente sem conflitos: Para mim é legal, do mesmo jeito que nós respeita elas [funcionárias], elas respeita também. (E1); Nada a reclamar, aqui cada um respeita o limite do outro. (E2). As falas demonstram que os funcionários compreendem os limites para o tratamento de usuários de álcool e outras drogas, não tendo imposições quanto a formas de tratamento. As observações mostraram grande aproximação entre os técnicos de enfermagem e os pacientes, sendo que são estes os profissionais que por mais tempo permanecem com os usuários.

Contudo, é possível ver a contradição nas falas apresentadas quando os usuários relatam não serem informados sobre o tratamento e a falta de assembleias e as falas apresentadas acima, em que mencionam uma convivência harmoniosa, uma vez que cada um respeitaria o limite do outro. Seria um respeito ao limite ou uma falta de diálogo e afazeres em que os pacientes se sentiriam muito livres no local?

As observações de campo demonstraram uma baixa proximidade entre a equipe de saúde de nível superior e os usuários do serviço, sendo o profissional de nível superior mais próximo dos pacientes, o enfermeiro. Já os técnicos de enfermagem foram os profissionais que lidavam de fato com os usuários, sendo muitas vezes com eles que os pacientes mais tinham atritos e ao mesmo tempo com quem mais conversavam. Os profissionais de saúde tinham uma aproximação maior durante os atendimentos individuais e durante as oficinas, que não eram realizadas de maneira regular.

Como já relatado, uma das falhas do CAPS ad é a comunicação, podendo esta ser facilitada através de grupos e/ou oficinas que são técnicas preconizadas pelo Ministério da Saúde para serem realizadas em CAPS ad. Mas, uma das queixas é o pouco número de atividades e a falta de continuidade ou periodicidade: O negócio é falta de atividade mesmo, fraca mesmo. (E16); A gente fica só pensando em ficar deitado dormindo. Tem nada pra fazer aqui. (E2); Eu acho que também poderia ter cursos pra gente, sabe? Fazer alguma coisa sei lá, um artesanato. (E2)

A falta de oficinas e de grupos faz com que os pacientes fiquem ociosos e sonolentos, foi observado que muitos levavam baralhos de carta para passar o tempo, sendo que jogavam entre si e com os técnicos de enfermagem, ou eram vistos dormindo no chão ou em papelões no pátio do serviço, pois o local tinha como uma das regras fechar a sala de multimídia e os dormitórios em certos horários para os pacientes se manterem acordados e em atividades, mas com a falta do comprimento da agenda de oficinas, os mesmos acabavam dormindo ou sentados no chão do pátio, reproduzindo a realidade que vivenciavam nas ruas.

O CAPS deveria, além da promoção de atividades voltadas para o tratamento do uso de álcool e outras drogas, também promover a inserção social desses usuários, sendo uma delas através da reinserção dos mesmos no mercado de trabalho. Assim, oficinas profissionalizantes ou até mesmo a criação de cooperativas e da economia solidária deveriam ser exploradas e propostas, mas no local não se encontram oficinas voltadas a esse fim.

Alguns usuários relataram essa falta de atividades profissionalizantes: Deveria ter um curso, uma educação. Alguma coisa assim. (E1); Uma oficina que pode nos garantir alguma coisa depois. (E15)

A falta de atividade pode levar o usuário a ter pensamentos recorrentes sobre o uso de drogas e levá-los até mesmo a abandonar o tratamento: Como costumo falar, mente vazia oficina do Diabo, se eu tô aqui 
o dia inteiro parado, tem hora que eu fico aqui o dia inteiro pensando em dar cinco hora pra sair, fazer meu "corre" e usar minha droga entendeu? Então não tem ocupação." (E15)

O que foi observado é que no local existe um cronograma com as atividades que deveriam ser realizadas, entretanto muitas vezes não ocorrem devido à sobrecarga dos profissionais com outras demandas, como acolhimentos, reuniões e demandas burocráticas, além do alto número de demandas individuais, sendo realizadas em consultas, que poderiam ser transformadas em assembleias ou grupos.

Com relação à infraestrutura do CAPS ad, nota-se que é improvisada. Muitas atividades que seriam realizadas juntamente com os grupos focais ficaram comprometidas em razão das instalações improvisadas, como a falta de local para atividades simultâneas e a falta de ventilação. A falta de banheiros também foi uma das reclamações: Outra coisa que eu acho que devia ter aqui... coitada das mulheres... as mulheres têm que ficar usando o banheiro dos homens, não dá certo esse trem. Então tinha que te um banheiro para as mulheres. (E3)

No entanto, apesar dos problemas relatados, o CAPS ad III foi visto pelos usuários como local de apoio e auxílio, como relatado nas seguintes falas: Pra mim é uma salvação né? É um apelo de vida que eu estou tendo, já tive vários né? Não dei valor, aqui pra mim tá sendo um dos melhores, por enquanto. (E1); O CAPS é um suporte, é um apoio sim, porque a gente ficava na rua. (E2)

Na cidade, o CAPS ad é o único local voltado para o acolhimento e tratamento dos usuários de SPA, sendo que as atividades de acolhimento e acompanhamentos dos mesmos pela APS ainda são insipientes.

Dessa forma, o CAPS ad se faz de extrema importância no tratamento dos usuários de álcool e droga, pois além de ser identificado como lugar de suporte pelos usuários é uma instituição que preconiza o sujeito e seus direitos, bem como tenta da melhor maneira possível apoiar e ajudar a superar o uso, além de ser acessível para todas as pessoas.

\section{Rede de Atenção psicossocial: percurso dos usuários}

O CAPS como discutido na sessão anterior é o único local na cidade que realiza o acolhimento da demanda dos usuários de álcool e outras drogas, realidade que dificulta a reinserção social do paciente e o tratamento no território.

A Rede de Atenção Psicossocial tem como objetivo ampliar o acesso da população em geral promovendo o atendimento às pessoas com sofrimento mental e com necessidades decorrentes do uso de drogas. No componente da Atenção Primária à Saúde (APS) foram estabelecidos os pontos de atenção, como unidades básicas de saúde, núcleos de apoio à saúde da família, consultórios de rua e centros de convivência.
Apesar da grande importância que tem a RAPS e o seu reconhecimento pelo usuário, ao se realizar o grupo focal relacionado ao percurso do usuário na Rede, percebeu-se que muitos dos participantes não sabiam o que era a RAPS e qual o seu objetivo e função, porém dois participantes falaram já terem utilizado outros serviços que estão dentro da rede, como a Unidade de Pronto Atendimento (UPA): A UPA, se não estiver bem, leva para lá, e lá não é bem atendido. (E16)

Com exceção da UPA, os outros serviços da RAPS não foram citados. Os dispositivos da rede acionados são os relacionados aos sinais e sintomas físicos, sendo pouco explorados e dada pouca importância aos componentes psicossociais do fenômeno.

O que se observou no local e em conversa com funcionários é uma dificuldade em se conseguir uma comunicação com os demais pontos da rede. Acredita-se na cidade que o paciente que é usuário de álcool e outras drogas "pertence" ao CAPS.

Se tem no papel a ideia de rede, mas na prática os profissionais e gestores não conseguiram formar de fato essa conexão, os demais domínios do fenômeno do uso, como as questões macrossociais, familiares e até mesmo psicológicas, não são abordados de forma integral, não favorecendo o tratamento do usuário.

A RAPS também demonstra falhas como em relação a "ter um lugar para ficar", ficou claro que alguns usuários dos CAPS ad o utilizam como ambiente de apoio social, de ter um local para ficar, e não apenas em busca da redução de danos devido às drogas.

São indivíduos em condições de vulnerabilidade social, sendo que os outros equipamentos da RAPS como casas de acolhimento e os serviços da Assistência Social ou não existem no município ou não se articulam com a área da saúde: Enquanto ela (mãe) não pega a casa eu tenho que fica andando de casa em casa de recuperação até ela pega (mãe) a casa. Assim, eu não tenho coragem, sou homem, mas admito, eu não tenho coragem de ir pra de baixo da ponte e dormir em cima de um papelão. (E9); Igual eu falei, "se tá fazendo tratamento com medicação", eu que não vou tomar remédio pra dormir na rua, porque eu sei as consequências que é dormir na rua, então eu tenho eu ficar aqui, entendeu? Que a maldade é demais. Então não adianta eles (profissionais CAPS ad) me passaram uma cartela desse tamanho e eu ir para a rua ali, chega um ali bota fogo em mim." (E15)

Os pacientes se encontram em grande vulnerabilidade social devido ao uso de drogas e acabam perdendo o seu local social, e quando a RAPS reproduz esse mesmo quadro o usuário tem poucas chances de uma reinserção social efetiva, precisando recorrer a redes alternativas de cuidado e suporte

Como foi dito por um dos praticantes sobre os alcoólicos anônimos e a igreja: Eu tô frequentando o AA, alcoólicos anônimos. Eu estou indo também na igreja 
evangélica, lá tô fazendo várias atividades com eles lá... e... é, é isso, estou fazendo tudo pra consegui largar. (E3); Eu saio (do CAPS ad) orando, pedindo a Deus, faço assim "o meu Deus, me ajuda, não me deixa bebe não". Vai me ajudando aí, me de força, preciso parar". Vou conversando com Deus, até eu chegar (em casa). Ajuda até eu chega em casa. (E4); Três anos que ela (mãe do paciente) está na igreja. Deus entrou e ela não bebe mais. (E6)

As redes alternativas são de grande valia e deveriam se articular mais com a rede formal de tratamento, já que para se conseguir o tratamento integral do usuário deve-se considerar todas as dimensões do cuidado, mas na prática diária do CAPS a religião e a articulação com entidades religiosas não ocorre.

\section{Discussão}

O CAPS ad é o local específico para o tratamento de usuários abusivos de álcool e outras drogas, sendo orientado pela estratégia de redução de danos (RD), prevenção, recuperação e reinserção social do indivíduo. A RD tem como objetivo a resolução dos problemas associados ao uso de SPA, sendo que a abstinência não é obrigatória e viria ao seu tempo(9).

Em virtude das dificuldades da Rede e das próprias dificuldades dos profissionais em entender e de fato realizar as ações de RD, o CAPS ad pode passar a ser um local de estadia e de "passar o tempo". Estudo realizado em Campinas (SP) corrobora com o presente estudo ao relatar que o CAPS ad seria utilizado mais como um suporte social do que especificamente para se trabalhar a redução de danos causados pelo uso de $\operatorname{SPA}^{(10)}$.

A falta de comunicação e de tempo para a realização de grupos é uma realidade não apenas nos CAPS, mas em todo o Sistema Único de Saúde (SUS) devido à grande burocratização do serviço, a cobrança para se atingir metas puramente quantitativas de procedimentos preestabelecidos, fazendo com que a equipe de saúde se torne refém de tabelas e gráficos de metas, não conseguindo de fato responder às demandas da população(11).

A relação entre profissionais de saúde e usuários do CAPS deveria ocorrer não apenas em consultas individuais, mas em grupos e oficinas. Quanto aos profissionais técnicos de enfermagem, as observações mostraram que seria necessária uma capacitação desses funcionários para abordar os usuários a fim de que a relação profissional/usuários não seja de amizade(12).

A enfermagem tem papel de destaque por estar na "linha de frente" do cuidado, sendo que a liderança do enfermeiro está vinculada a sua formação acadêmica, que abrange disciplinas como administração, gerência e outras que trabalham com o âmbito psicossocial e biológico, fazendo desses profissionais aptos a atuarem como importantes formadores de vínculos, sendo essa capacidade observada quando se nota que dos profissionais de nível superior é o que mais se aproxima dos usuários ${ }^{(12)}$.

As oficinas no local não possuem uma regularidade como demonstrado, o que é uma lacuna no tratamento, uma vez que as atividades promovidas no CAPS são essenciais, devendo ser alternativas para lazer e atividades livres de SPA. As oficinas, por exemplo, além de conter atividades manuais, devem abranger atividades de geração de renda, pensando em um possível futuro profissional do paciente. Fato que preocupa os pacientes, como foi demonstrado(13).

Quanto à articulação do CAPS, este deveria estar articulado a outros dispositivos da rede como os consultórios de rua, os leitos em hospitais públicos e as casas de acolhimento e a Estratégias de Saúde da Família $(\text { ESF })^{(14)}$. Porém, muitas vezes, os CAPS ad atuam isolados no tratamento aos usuários de álcool e outras drogas, sendo pautados em encaminhamentos para o restante da RAPS(4). Fato que foi percebido no presente estudo, no qual, além das lacunas na rede, a comunicação não ocorre em Rede, mas em vias de mão única, ficando o paciente sozinho tentando percorrer os dispositivos existentes.

A integração dos serviços, além de facilitar o acesso ao usuário, também é capaz de promover o reconhecimento precoce de agravos criando estratégias para que o indivíduo tenha a menor perda possível de funções sociais, familiares e físicas ${ }^{(3,15)}$.

Se a APS reconhecesse e acolhesse inicialmente esses usuários, assim como promovessem ações que visassem à prevenção e promoção de saúde mental, isso diminuiria os custos em saúde e o menor número de encaminhamentos ou de livre demanda para os CAPS Ad ${ }^{(15)}$.

A Organização Mundial de Saúde preconiza que países com média e baixa renda invistam na integração da saúde mental na Atenção Primária de Saúde como forma de contenção de despesas. Países como a África do Sul, Nigéria e outros países africanos já planejam ou começaram a se articular para essa integração(16). E países desenvolvidos como Inglaterra e Holanda já efetivaram essa incorporação, sendo que a Holanda fez uma grande reforma no âmbito da saúde mental no ano de 2012 com as intervenções nessa área incorporadas na Atenção Primária em Saúde(17).

Uma das formas que o Ministério da Saúde fez para auxiliar a integração da Rede, principalmente com a APS, foi a criação do Apoio Matricial, as equipes são denominadas de Núcleos de Apoio à Saúde da Família (NASF). Constitui-se um dispositivo terapêutico para discussões de casos entre as equipes, atendimentos mais específicos para familiares e usuários, além de promover espaços para a comunidade se expressar e participar da construção da saúde do território(17).

$\mathrm{Na}$ cidade, as NASF ainda são em número insuficientes, o que prejudica esse intercâmbio entre APS e Atenção Secundária, assim como não há equipes de consultório de rua, que são peças fundamentais para a 
promoção e prevenção de saúde da população de rua e que consequentemente podem fazer uso de álcool e outras drogas ${ }^{(4)}$. Assim, a maior parte do cuidado ao usuário de álcool e outras drogas fica a cargo do CAPS ad.

Com as dificuldades de articulação da RAPS, os pacientes acabam procurando redes alternativas, como os grupos de autoajuda, que são locais que através do trabalho em grupo e do exemplo de outros indivíduos que vivenciam as mesmas situações conseguem modificar todo um quadro situacional. Todas as formas de auxílio são positivas quando se trabalha com usuários de SPA. A convivência com indivíduos recuperados ou em processo de recuperação é vista como benéfico para o usuário de drogas ${ }^{(18)}$.

Quanto à religião, estudos corroboram esse item ao citarem esta como uma estratégia de enfrentamento(18). A religião aproxima-se de uma oferta/ resposta ao associar o uso de SPA ao distanciamento de Deus, assim quando o indivíduo se volta à crença religiosa ele passa a pertencer a uma nova comunidade e se reencontra com Deus.

A recuperação de um usuário de drogas se dá através de vários componentes, em uma pessoa religiosa há um aumento da autoestima por meio de uma expansão da sua valorização em uma comunidade religiosa, o que facilita sua recuperação(19). O CAPS juntamente com o restante da RAPS deve saber articular entre si e com as redes alternativas de cuidado.

Por se ter apenas um CAPS ad na cidade e sua abertura ser recente, os usuários e população em geral ainda encontram dificuldades em compreender os seus objetivos e utilidade no tratamento do uso de álcool e outras drogas. Com uma aproximação maior da Atenção Primária em Saúde e fortalecimento dos outros mecanismos da Rede de Saúde talvez de tenha um entendimento melhor sobre a atuação do local e consequentemente uma melhoria do serviço.

Com esse quadro o estudo possui a limitação de ter sido realizado em apenas um local, assim como não buscou outros usuários de álcool e drogas que frequentam outros pontos da RAPS para conhecer suas visões sobre seus percursos, o que seria de extrema importância ao se traçar outros erros e acertos da rede. Todavia, dentro do que foi proposto, o presente estudo conseguiu captar o olhar desse usuário quanto ao seu tratamento e entendimento quanto à RAPS.

\section{Conclusão}

Esta pesquisa teve como objetivo conhecer qual a visão e o percurso do usuário de SPA no CAPS ad e no restante da RAPS. Como pesquisa qualitativa procurou aprofundar e conhecer a visão do outro sobre o assunto em uma dada realidade, assim não se consegue encerrar o assunto ou fazer afirmativas generalizadas, mas com base na discussão esta é uma realidade que se aproxima de outras realidades nacionais.
O fortalecimento da RAPS é fundamental para que o usuário de SPA possa ter seus direitos de cidadão garantidos, para isso é necessário empoderá-lo e isso, apenas, será possível a partir do momento que este for protagonista do seu tratamento. Os CAPS ad como um dos principais dispositivos deve fortalecer essa participação do usuário através da reinserção social.

A APS deve ser a porta de entrada para qualquer cidadão, incluindo-se os usuários de SPA. Para melhorar essa entrada e comunicação entre APS e CAPS ad é necessário que as equipes de ambas sejam capacitadas e possam compreender qual o seu papel perante o usuário de drogas. As universidades devem ter em suas grades disciplinas voltadas à saúde mental, que sejam abrangentes, não se limitando apenas às psicopatologias para que os futuros profissionais sejam capazes de captar todas as dimensões do fenômeno.

E por fim, nem o CAPS ad sozinho ou a APS consegue atender esses indivíduos, é urgente que os consultórios de rua, casas de acolhimento e leitos em hospitais gerais estejam operantes e assim, de fato, se tenha uma Rede de Atenção integral.

\section{Agradecimentos}

Ao núcleo de Pesquisa Gestão, Sociedade e Epidemiologia na Enfermagem e na Rede de Atenção à Saúde (GSEERAS) da Universidade Estadual de Minas Gerais.

\section{Referências}

1. Frose RV, Tersser CD. Mental health care practices in primary health care: an analysis based on experiences developed in Florianópolis, Brazil. Ciênc Saúde Coletiva. [Internet]. 2015 [cited 2018 Apr 10]; 20(10):3151-61. Available from: http://www.scielo.br/scielo.php?script=sci_ arttext\&pid=S1413-81232015001003151\&lng=en

2. Vasconcelos MGF, Jorge MSB, Pinto AGA, Pinto DM, Simões ECP, Maia JP Neto. Práticas inovadoras de saúde mental na atenção básica: apoio matricial na redefiniçao do processo de trabalho em saúde. Cad Bras Saúde Mental. [Internet]. 2012 [Acesso 15 abr 2018];4(8): 166-75. Disponível em: incubadora.periodicos.ufsc.br/ index.php/cbsm/article/download/2031/2327

3. Hirde A. A perspectiva dos profissionais da atenção primária a saúde sobre o apoio matricial em saúde mental. Ciênc Saúde Coletiva. [Internet]. 2015 [Acesso 10 abr 2018];20(2):371-82. Disponível em: http://www.scielo.br/scielo.php?pid=S141381232015000200371\&script=sci_abstract\&tlng=pt

4. Gryschek G, Pinto AAM. Mental health care: how can Family Health teams integrate it into Primary Healthcare? Ciênc Saúde Coletiva. [Internet]. 2015 [cited 2018 May 18]; 20(10):325562. Available from: http://www.scielo.br/ 
scielo.php?script $=$ sci_arttext $\&$ pid $=$ S 1413 $81232015001003255 \& \mathrm{Ing}=\mathrm{en} \& \mathrm{nrm}=$ iso

5. Breilh J. Episteme e práxis social: como se transformam, avançam ou retrocedem os conceitos cientificos. In: Breilh J. Epidemiologia crítica: ciência emancipadora e interculturalidade. Rio de Janeiro (RJ): Editora FIOCRUZ; 2006.

6. Lervolino AS, Pelicioni MCF. A utilização do grupo focal como metodologia qualitativa na promoção da saúde. Rev Esc Enferm USP. [Internet]. 2015 [Acesso 18 maio 2018]; 35(2):115-21. Disponível em: http://www. scielo.br/scielo.php?script $=$ sci_arttext $\&$ pid $=$ S008062342001000200004\&lng=en

7. Habermans J. Dialética e hermenêutica. Porto alegre(RS): LPM; 1987.

8. Minayo MCS Técnicas de análise do material qualitativo. In: Minayo MCS. O desafio do conhecimento: pesquisa qualitativa em saúde. São Paulo (SP): Hucitedc; 2014. p. 303-60.

9. Medeiros, Regina. Social construction of drugs and crack and the institutional responses and therapeutic approaches. Saúde Soc. [Internet]. 2014 [cited 2018 Jun 5]; 23(1):105-17. Available from: http://www. scielo.br/scielo.php?script $=$ sci_arttext\&pid $=$ S010412902014000100105\&lng=en.

10. Lacerda CB, Rojas MF. Significados e sentidos atribuídos ao Centro de Atenção Psicossocial Álcool e outras Drogas (CAPS AD) por seus usuários: um estudo de caso. Interface. (Botucatu) [Internet]. 2017 [Acesso 18 maio 2018]; 21(61):363-72. Disponível em: http://www.scielo.br/scielo.php?script $=$ sci_ arttext\&pid=S1414-32832017000200363\&lng=en\&nrm =iso

11. Ribeiro HMCB, Lamy ZC, Coimbra LC, Rocha LJLF, Aquino DMC, Coutinho NPS, et al. Representações sociais de profissionais de núcleos de apoio a saúde da família sobre interdisciplinaridade. Trab Educ Saúde. [Internet]. 2015 [Acesso 15 abr 2018]; 13(suppl 2): 97-115. Disponível em: http://www.scielo.br/scielo. php?Script=sci_arttext\&pid=S1981-77462015000500097 12. Lanzoni GMM, Meireles BHS, Cummings G. Nurse leadership practices in primary health care: $A$ grounded theory. Texto Contexto Enferm. [Internet]. 2016 [cited 2018 May 10]; 25(4):e4190015. Available from: http://www.scielo.br/scielo.php?script=sci_ arttext\&pid $=$ S0104-07072016000400305\&lng=en\&nrm $=$ iso

13. Gonçalves $\mathrm{H}$ et al. Adverse childhood experiences and consumption of alcohol, tobacco and illicit drugs among adolescents of a Brazilian birth cohort. Cad Saúde

Autor correspondente:

Camila Souza de Almeida

E-mail: csalmeida_1@hotmail.com

(iD) https://orcid.org/0000-0002-7032-0945
Pública. [Internet]. 2016 [cited 2018 Jun 07]; 32(10): e00085815. Available from: http://www.scielo.br/scielo. php?script=sci_arttext\&pid $=$ S0102-311X201600100500 9\&Ing=en\&nrm=iso

14. Costa ACQ, Raposo JCS, Valença PAM, Santos CFBF, Amorim VCSA. Álcool e comportamento sexual entre estudantes do ensino médio no Brasil. Adolesc Saúde. [Internet]. 2017 [Acesso 12 maio 2018]; 14(3): 24-9. Disponível em: http://www.adolescenciaesaude.com/ detalhe_artigo.asp?id $=668$

15. Pinto AG, Jorge MSB, Vasconcelos MGF, Sampaio JJC. Lima GP, Bastos VP, et al. Apoio matricial como dispositivo do cuidado em saúde mental na atenção primária: olhares múltiplos e dispositivos para resolubilidade. Ciênc Saúde Coletiva. [Internet]. 2012 [Acesso 14 abr 2018]; 17(3):653-60. Disponível em: http://www.scielo.br/scielo.php?script $=$ sci_ arttext\&pid $=$ S1413-81232012000300011\&lng=en\&nrm =iso

16. Mugisha J, Abdulmalik J, Hanlon C, Petersen I, Lund C, Upadhaya, et al. Health systems context(s) for integrating mental health into primary health care in six Emerald countries: a situation analysis. Int J Ment Health System. [Internet]. 2017 [cited 2018 May 18]; 11:7 Available from: https://ijmhs. biomedcentral.com/track/pdf/10.1186/ s13033-016-0114-2?site=ijmhs.biomedcentral.com

17. Magnée $T$, Beurs DP, Boxem R, de Bakker DH, Verhaak PF. Potential for substitution of mental health care towards family practices: an observational study. BMC Fam Pract. [Internet]. 2017 [cited 2018 Mar 24]; 18(1). Available from: https://www.ncbi.nlm.nih.gov/ pmc/articles/PMC5282718/

18. Pedroso RS, Kessler F, Pechansky F. Treatment of female and male inpatient crack users: a qualitative study. Trends Psychiatr Psychother. [Internet]. 2013 [cited 2018 May 18]; 35 (1):36-45 Available from: http://www.scielo.br/pdf/trends/v35n1/a05v35n1.pdf 19. Rocha MLA, Guimarães MBL, Cunha MB. The recovery process of drug misuse in the pentecostal church Assembly of God. Interfac.e (Botucatu). [Internet]. 2012 [cited 2018 May 15]; 16 (40):177-90. Available from http://www.scielo.br/scielo.php?script=sci_ arttext\&pid =S1414-32832012000100014\&lng=en\&nrm $=$ iso

Recebido: 22.10.2018 Aceito: 30.01 .2019

Copyright $\odot 2019$ SMAD, Rev. Eletrônica Saúde Mental Álcool Drog. Este é um artigo de acesso aberto distribuído sob os termos da Licença Creative Commons CC BY-NC.

Esta licença permite que outros remixem, adaptem e criem a partir do seu trabalho para fins não comerciais, e embora os novos trabalhos tenham de lhe atribuir o devido crédito e não possam ser usados para fins comerciais, os usuários não têm de licenciar esses trabalhos derivados sob os mesmos termos. 